\title{
КОМПАРАТИВНЫЙ АНАЛИЗ УРОВНЯ КЛАСТЕРИЗАЦИИ СОЦИАЛЬНО- ЭКОНОМИЧЕСКИХ СИСТЕМ В РОССИЙСКОЙ ФЕДЕРАЦИИ И ЗАРУБЕЖНЫХ ГОСУДАРСТВАХ
}

\author{
(c) 2021 Гусев Валерий Владимирович \\ доктор экономических наук, профессор
}

Московский государственный университет технологий и управления имени К. Г. Разумовского

(Первый казачий университет), Россия, Москва

(c) 2021 Рябова Таисия Фоминична

доктор экономических наук, профессор

Московский государственный университет технологий и управления имени К. Г. Разумовского

(Первый казачий университет), Россия, Москва

(c) 2021 Аничкина Ольга Александровна

кандидат экономических наук, доцент

Московский государственный университет технологий и управления имени К. Г.Разумовского

(Первый казачий университет), Россия, Москва

(c) 2021 Егоров Егор Станиславович

Московский государственный университет технологий и управления имени К. Г. Разумовского (Первый казачий университет), Россия, Москва

В статье представлен компаративный анализ некоторых показателей уровня кластеризации социально-экономических систем в Российской Федерации и развитых зарубежных странах, вычленены основные модели кластеризации, рассмотрены приоритетные направления их возможного применения в России.

Ключевые слова: кластер, кластеризация, кластерная политика, показатели кластеризации, зарубежный опыт, модели декомпозиции, дирижистская и либеральная кластерная политика.

Одним из важнейших механизмов стимулирования развития социально-экономических систем в развитых государствах мира в XX1 веке стала кластеризация организаций

Под кластеризацией в данной статье понимается интеграция разнородных хозяйствующих субъектов в кластер. Кластер - это комплекс социально-экономических субъектов, характеризующихся различной институциональной сущностью, но имеющих значимую корреляционную связь между собой, интегрированных в единую целостную систему с помощью разнообразных институциональных, рыночных, технико-технологических, долгосрочных кооперативных связей, для которых характерна достаточно высокая концентрация производства и капитала в конкретном регионе, необходимая для получения синергетического эффекта и повышения эффективности совместной хозяйственной деятельности. Кластеризация стимулирует инновационную деятельность организаций, образующих кластер.
По результатам рейтинга Global Innovation Index (GII - 2020) следует, что Россия занимает 47 позицию по уровню инновационного развития из 131 государства, включённого в опрос.

По отношению к результатам 2015 г. Россия поднялась на две позиции. В то же время необходимо обратить внимание на то, что она в значительной степени отстаёт от стран, занимающих ведущие места по показателям кластерного развития. Уровень кластерной концентрации в России равен 0,3, интегральная оценка по GII составляет 3,4 балла из возможных 7 баллов, а находится в данном рейтинге Россия на 95 позиции (таблица 1).

Сведения о ситуации кластеризации в России в данном рейтинге, вероятно, обусловлены созданием 75\% кластеров только после 2012 г., что подтверждает их нахождении на начальном этапе формирования и развития в настоящий момент [1].

Анализ результатов исследования опыта теории и практики кластеризации социально- 
Таблица 1. Показатели уровня кластеризации ряда государств мира в 2018-2020 гг.

\begin{tabular}{|l|l|c|c|l|c|c|l|c|c|}
\hline \multicolumn{2}{|c|}{} & № & $\begin{array}{c}\text { Интегра- } \\
\text { Льная } \\
\text { оценка } \\
2018 \text { г. }\end{array}$ & Место & Страна & $\begin{array}{c}\text { Инте- } \\
\text { гральная } \\
\text { оценка } \\
2019 \text { г. }\end{array}$ & Место & Страна & $\begin{array}{c}\text { Интегра- } \\
\text { льная } \\
\text { оценка } \\
2020 \text { г. } \\
\text { стерная } \\
\text { концент- } \\
\text { рация } \\
2020 \text { г. }\end{array}$ \\
\hline 1 & США & 5,7 & 1 & Италия & 5,5 & 1 & США & 5,5 & 1 \\
\hline 2 & $\begin{array}{l}\text { Швейца- } \\
\text { рия }\end{array}$ & 5,5 & 2 & Германия & 5,4 & 2 & Китай & 5,4 & 0,99 \\
\hline 4 & $\begin{array}{l}\text { Нидер- } \\
\text { ланды }\end{array}$ & 5,4 & 3 & $\begin{array}{l}\text { Швейца- } \\
\text { рия }\end{array}$ & 5,3 & 3 & $\begin{array}{l}\text { Швейца- } \\
\text { рия }\end{array}$ & 5,3 & 0,98 \\
\hline 5 & Китай & 5,4 & 4 & Китай & 5,3 & 4 & Германия & 5,3 & 0,98 \\
\hline 6 & Япония & 5,3 & 5 & $\begin{array}{l}\text { Нидер- } \\
\text { ланды }\end{array}$ & 5,2 & 5 & $\begin{array}{l}\text { Великоб- } \\
\text { ритания }\end{array}$ & 5,3 & 0,97 \\
\hline
\end{tabular}

экономических систем в зарубежных странах подтверждает эффективность применения кластерной модели регионов. Изучение опыта прогрессивных государств подтверждает перспективность использования моделей кластеризации, как наиболее эффективного метода концентрации ресурсов, производства и человеческого капитала. Опыт стран всего мира является подтверждением того, что повышение конкурентоспособности региона возможно посредством осуществления кластерной политики в регионе. Для большинства развитых стран наличие отраслевых кластеров является своего рода привычным видом формирования объединений [2].

В результате проведённого анализа кластерных инициатив в государствах разных континентов, выполненных за 20 последних лет, можно согласиться с выводом, что высокая концентрация ресурсов, производства и человеческого капитала при создании отраслевых кластеров обеспечивают развитие производства, рост производительности труда, эффект ресурсосбережения, повышение конкурентоспособности производимых товаров, улучшение качества жизни, снижение безработицы за счет открытия новых рабочих мест, снижение трудоемкости товаров, рост объема товарооборота, рост величины валового внутреннего продукта. Опыт таких стран мира как США, Япония, Германия, КНР, Финляндия, Франция, Канада, Нидерланды и др., которые как первооткрыватели накопили громадный опыт по созданию объектов кластеризации, пытаются освоить и другие государства.

Принцип кластеризации организаций первыми был использован в США при создании
Кремниевой долины, на территории которой размещено примерно 90 тысяч предприятий различного вида деятельности, а также множество научно- исследовательских объектов и несколько крупных университетов региона.

Кремниевая долина, как уникальная структура, может считаться образцом эффективного сотрудничества научных и предпринимательских центров, академических и иных организаций. Помимо перечисленных звеньев в структуру Кремниевой долины входит около 700 банков, примерно190 венчурных фирм, которые в условиях тесной взаимосвязи, обеспечивают финансирование инициативных компаний [3].

Следующим примером инициативы можно считать эксклюзивный образец деятельности Японии, которая на поприще кластеризации значительно отличается от США. В этой стране инновациями считаются, кроме принципиально новых выработанных принципов и решений, методов и механизмов трансформации, способы повышения производительного труда [4].

В Германии кластеры классифицирует на три группы:

1. Кластеризация, специализирующаяся на сквозных технологиях, таких как нанотехнологии, мехатроника и др.;

2. Кластеризация производственных объединений;

3. Кластеризация высокотехнологичных структур, например, организаций аэрокосмической отрасли промышленности.

В Финляндии кластерная модель начала применяться ещё в XX веке. С 1990 г. в качестве основных критериев было принято отношение стоимости товара, производимого кластером, 
к размеру мирового ВВП и к величине объёма мировой торговли. Крупнейшим кластером Финляндии, обладающим высокой эффективностью, считается лесной, в котором функционирует около 10 крупных кластеров.

В Нидерландах при определении важнейших приоритетов инновационной политики государства [5] крупными или сильными кластерами считаются только те из них, которые обеспечивают получение производственных результатов, предусмотренных программой выпуска.

В Великобритании кластеры классифицируют по регионам. Кластеры северной части страны специализируются на организациях промышленной сферы, а южной части - на сфере услуг [6].

Рассмотрим кластерную модель, применяемую во Франции. Политика страны в области инноваций и развития кластеров преследует цель активизации сотрудничества индустриальных организаций, ВУЗов и научно-исследовательских центров, развитие малых и средних организаций. На данный момент во Франции осуществляют деятельность при поддержке со стороны государства свыше 70 кластеров. Более 10 лет правительство Франции активизирует развитие кластеров посредством оказания всесторонней поддержки. Для кластерной политики Франции характерно важное ноу-хау. Оно реализуется программой финансирования межкластерного взаимодействия. Государство принимает участие в финансировании управляющих компаний кластеров в пропорции 50/50 [7].

В качестве одного из успешных кластеров Франции можно выделить «Cap Digital». В его состав входит около 1000 участников. Большую часть организаций составляют малые и средние предприятия. Управляющая компания «Сар Digital» находится в Париже. Она состоит из 43 сотрудников. Финансирование управляющей компании осуществляется за счёт доходов от платных услуг, взносов участников, а также республиканского и регионального бюджета (по 25\%). На финансирование управляющей компании в год уходит около 7 млн. евро. Управляющая компания оказывает следующие услуги: организация встреч и семинаров, обеспечение доступа к базам данных, разработка программы роста и т.д. [8]

Кластеры Португалии обладают особенностью, которая была определена при реализации программы М.Портером при исследовании уровня развития конкурентоспособности экономики этой страны. Большинство кластеров Португалии сформированы по территориальному признаку, но при этом для них характерен низкий уровень взаимодействия внутри кластера [9].

В Испании существует всего 142 кластера, большинство из которых ориентированы на традиционные отрасли промышленности [10].

Кластерный подход Канады характеризуется наличием опыта в реализации кластерных инициатив (кластер пищевой промышленности, биотехнологический кластер, винодельческий кластер и т.п.). Опыт, накопленный у Канады по формированию комплексных региональных кластеров, состоящих из множества промышленных кластеров, для России представляет особый интерес. Вместе с тем, кластерные инициативы Канады имеют всестороннюю поддержку со стороны органов власти. При этом содействие процессу кластеризации оказывается на федеральном, региональном и муниципальном уровнях.

В настоящее время весьма активно развивается процесс создания региональных кластеров в Китае, Сингапуре и Юго-Восточной Азии.

Кластеры «Шанхайской зоны», являющиеся лидерами в КНР, осуществляют свою деятельность в соответствии со специальной моделью производства. Она характеризуется использованием кластерами, расположенными в одном регионе, природного, интеграционного и кадрового потенциалов регионов, расположенных поблизости [11].

Анализ опыта зарубежных государств в создании кластеров свидетельствует о применении в них, с одной стороны, некоторых общих подходов, а, с другой стороны, использовании в каждой стране ряда особенностей. В качестве таких особенностей выступают, например, государственная поддержка конкретных отраслей, природно-ресурсный и национальнодемографический потенциалы региона, а также определение приоритетности в конструировании кластеров.

Анализ этого обуславливает необходимость применения в России собственных подходов формирования региональных кластеров с учётом сложившихся экономических условий.

Результаты исследования опыта зарубежных стран свидетельствуют о наличии у них двух ключевых моделей, на базе которых реализуется политика кластеризации: либеральная и дирижистская. 
Ключевой принцип либеральной кластерной стратегии заключается в моделировании кластера как рыночного организма, в котором государство принимает пассивное участие. Оно устраняет факторы, которые затрудняют его естественное развитие. Данная стратегия используется в странах, где по традиции осуществляется либеральная экономическая политика (Австралия, Великобритания, Канада, США).

Дирижистская кластерная политика состоит из ряда мер, включая выбор важнейших направлений финансирования программ, ориентированных на развитие кластеров региона и формирование необходимых для их успешного развития условий. Осуществление этой политики характерно для стран, принимающих активное участие в экономической жизни государства (Южная Корея, Сингапур, Франция, Швеция, Япония и др.). Данные страны принимают непосредственное участие в создании кластеров [12].

Государства, придерживающиеся данной стратегии, определяют регион для формирования кластера, устанавливают объём его финансирования и целенаправленно формируют инфраструктуру для наиболее важных кластеров. В таблице 2 отражены страны, в которых используются либеральная и дирижистская модели.

Дирижистская и либеральная модели кластеризации имеют ряд серьезных отличий: [13]

1. При организации либеральной модели кластеризации объекту предоставляется выбор преимуществ и обеспечено ее развитие при поддержке имеющимся рынком. Когда применяется дирижистская модель кластеризации, используется другой подход. В этом случае государство самостоятельно выбирает отраслевые и региональные кластерные объекты, составляет планы реализации своей политики, необходимые для активного развития по всем основным направлениям деятельности.

2. Дирижистская модель кластера должна быть адекватной выбранному региону, то есть его климатическим и демографическим условиям, структуре, развития производственной деятельности, номенклатуре выпускаемых товаров, инфраструктуре, наличию квалифицированного человеческого и интеллектуального потенциа- лов, а также объему финансирования объекта. Когда формируется либеральная модель кластера, необходимо учитывать объем стимулов, предоставляемых их властным руководителям, на которых возложена ответственность за организацию и эффективность функционирования отраслевого кластера.

3. В дирижистской модели кластерной политики отмечается намеренное создание совершенной инфраструктуры (трубопроводов, линий передачи электрической энергии и связи, шоссейных магистралей и железных дорог, аэропортов, водных путей и др.) для наиболее важных кластеров. В то же время в государствах либерального типа не наблюдается их активного участия в создании кластерной развитой инфраструктуры.

В процессе исследования установлено, что большинству европейских государств свойственна организация крупных кластерных структур в важнейших отраслях промышленности и сопутствующих сферах экономики. Наряду с этим, кластерные структуры, как правило, создают новые рабочие места, повышают интеллектуальный потенциал, что способствует повышению человеческого капитала, организуя активный труд и вовлечение значительных слоев населения в конкретную производственнотехнологическую деятельность. Опыт процесса кластеризации, накопленный в ведущих странах мира, характеризуется общественной новизной многих векторов производства, ростом масштабов деятельности организаций, повышением уровня профессионализма персонала, расширением интеллектуального труда, ростом заработной платы, улучшением условий жилья, развитием новых форм образования, созданием передовых методов лечения населения, повышением культуры жизни и ростом валового внутреннего продукта. Генерирование новых кластерных систем крупных конгломератов повышает эффективность финансовоэкономических результатов, снижает трудозатраты на выполнение производственных операций, что выгодно участникам кластеров, самому кластерному объекту, региону и стране в целом.

Таблица 2. Либеральная и дирижистская модели кластеризации некоторых стран мира

\begin{tabular}{|l|l|}
\hline \multicolumn{1}{|c|}{ Вид модели } & \multicolumn{1}{c|}{ Страны } \\
\hline Дирижистская & Германия, Франция, Финляндия, Япония, Китай, Австрия, Индия \\
\hline Либеральная & США, Италия, Великобритания, Канада \\
\hline
\end{tabular}


Таблица 3. Группировка европейских стран мира по отраслевому признаку кластеризации

\begin{tabular}{|l|l|}
\hline \multicolumn{1}{|c|}{ Сферы кластеризации } & \multicolumn{1}{c|}{ Страны } \\
\hline 1. Машиностроение, электроника. & Германия, Италия, Нидерланды, Норвегия, Ирландия, Швейцария. \\
\hline 2. Биотехнологии и биоресурсы. & Германия, Великобритания, Норвегия, Франция, Нидерланды. \\
\hline 3. Фармацевтика, косметика. & Франция, Италия, Дания, Германия, Швеция. \\
\hline $\begin{array}{l}\text { 4. Пищевая промышленность. сельское } \\
\text { хозяйство. }\end{array}$ & Нидерланды, Финляндия, Италия, Бельгия, Франция. \\
\hline $\begin{array}{l}\text { 5. Нефтегазовый и химический ком- } \\
\text { плексы }\end{array}$ & Германия, Швейцария, Бельгия. \\
\hline $\begin{array}{l}\text { 6. Электронные технологии, связь, } \\
\text { информационные технологии }\end{array}$ & Швейцария, Финляндия \\
\hline 7. Здравоохранение & Швеция, Дания, Швейцария, Нидерланды \\
\hline 8. Лесобумажный комплекс & Финляндия \\
\hline 9. Коммуникации и транспорт & Нидерланды, Норвегия, Ирландия, Дания, Финляндия, Бельгия \\
\hline 10. Строительство & Финляндия, Бельгия, Нидерланды. \\
\hline Легкая промышленность & Финляндия, Италия, Дания, Швейцария, Швеция, Австрия. \\
\hline Энергетика & Норвегия, Финляндия. \\
\hline
\end{tabular}

На основе проведённого анализа можно утверждать, что в процессе создания кластерной модели, органы власти, производственнотехнологические и научные организации выполняют важную роль в развитии экономики страны и регионов [14]. В таблице 3 приведены сферы кластеризации, характерные для экономики развитых стран европейского континента.

Представленная в таблице 3 информация о специализации кластеризации, соответствует конкурентным преимуществам и уровню развития европейских стран. Вместе с тем у любого кластера имеется потенциальная возможность изменения направления инновационной деятельности. Кластеры, осуществляющие деятельность в направлениях «новой экономики» позволяют повысить эффективность экономической системы государства. Векторы инновационных кластеров не должны дублировать традиционные направления экономики государства. Наибольшей востребованностью в экспорте стран пользуется именно конкурентоспособная продукция. В свою очередь, это дает возможность определить в каких направлениях экономики целесообразнее использовать кластерную модель.

Анализ международной практики процесса кластеризации позволяет сделать следующие выводы:

1. Применение кластерной модели выступает в качестве объективного этапа развития экономики, а ее распространение является важной чертой всех высокоразвитых государств.

2. Общей чертой развития кластеризации социально-экономических систем в зарубежных странах является всё более широкое применение кибернетизации в технологических и управленческих процессах. Она ускоряет процесс кластеризации, а также динамику принятия решения и его исполнения в отдельных его звеньях и в целом по кластеру.

3. Характерной особенностью крупного кластера состоит в повышении конкурентоспособности, как всего кластера, так и каждой организации, входящей в него;

4. Кластерная политика осуществляется посредством интеграции, организованной государственными и региональными структурами, коммерческими организациями, а также научно-исследовательскими институтами и другими хозяйствующими субъектами с целью объединения их усилий для повышения эффективности деятельности всего кластера за счёт увеличения уровня инновационности каждого звена в отдельности и в целом кластерной социально-экономической системы.

В результате проведённого компаративного анализа уровня кластеризации социальноэкономических систем в Российской Федерации и зарубежных государствах констатируется, что динамика создания кластеров и уровень эффективности их функционирования в России существенно уступает развитым странам. Уровень кластерной концентрации России равен 0,3 ; интегральная оценка по GII составляет 3,4 балла из возможных 7 баллов. На основании приведённых цифр рейтинг РФ в 2019 г. определялся 95 местом. 
Однако можно утверждать, что в мировом масштабе не существует одинаковых моделей создания кластеров или однотипных подходов по их организации. Страны мира в зависимости от исторического опыта, традиций и уровня своего развития формируют специфические концепции образования и регулирования созданных кластеров. При этом организация кластерных структур осуществляется государственными органами в соответствии с возложенными обязанностями и функциями осуществления национальной индустриальной стратегии, способствующей повышению процессов цифровизации, наукоёмкости, конкурентоспособности и индустриализации выделенных территорий.

Для наращивания экономического потенциала Российская Федерация может и должна использовать механизм кластеризации в своих регионах с учётом их специфики и позитивного опыта, накопленного в зарубежных государствах.

\section{Библиографический список}

1. Цифровая трансформация в России - 2020 [Электронный ресурс] - Режим доступа: https://ict.moscow/ research (дата обращения 21.10.2021).

2. Меньшенина И. Г. Кластерообразование в региональной экономике: монография. Екатеринбург, 2008. С. 78

3. Рыхтик М.И. Национальная инновационная система США: история формирования, политическая практика, стратегия развития. Нижний Новгород, 2011. С. 17.

4. Фролов А.В. Формирование кластерной стратегии развития экономики региона: автореф. дисс. канд. экон. наук. Оренбург, 2013. С. 15.

5. Ксенофонтова О.Л. Опыт зарубежных стран по созданию и функционированию кластеров: модельный подход // Современные наукоемкие технологии. Региональное приложение. 2015. № 2 (42). С. 37.

6. Меньшенина И.Г. Кластерообразование в региональной экономике: монография. Екатеринбург, 2008. С. 79.

7. Просалова В.С. Теоретические подходы к формированию понятия кластера, его специфические признаки и классификация // Фундаментальные исследования. 2016. № 5. С. 187.

8. Стефанова Н.А. Понятие и общие принципы формирования кластеров цифровой экономики в России // Азимут научных исследований: экономика и управление. 2018. Т. 7. № 1(22). С. 239.

9. Фролов А.В. Формирование кластерной стратегии развития экономики региона: автореф. дисс... канд. экон. наук. Оренбург, 2013. С. 16.

10. Global Innovation Index for 2018-2020. [Электронный ресурс] - Режим доступа: URL: https://www. globalinnovationindex.org (дата обращения 21.10.2021).

11. Цифровая экономика [Электронный ресурс] - Режим доступа: https://issek.hse.ru/ (дата обращения 21.10.2021).

12. Ксенофонтова О.Л. Опыт зарубежных стран по созданию и функционированию кластеров: модельный подход // Современные наукоемкие технологии. Региональное приложение. 2015. № 2 (42). С. 38.

13. Ксенофонтова О.Л. Опыт зарубежных стран по созданию и функционированию кластеров: модельный подход // Современные наукоемкие технологии. Региональное приложение. 2015. № 2 (42). С. 39.

14. Ленчук Е.Б., Власкин Г.А. Кластерный подход в стратегии инновационного развития зарубежных стран // Проблемы прогнозирования. 2010. № 5. С. 49. 